\title{
Topiramate and rhegmatogenous retinal detachment
}

Sir,

We read with interest the letter by Dey et al., about Topiramate and Rhegmatogenous Retinal Detachment (RRD) ${ }^{[1]}$ It is a good observation. However, we disagree with the basic presumption that topiramate caused the RRD which these two patients have suffered. Flashes of light and floaters are signs of acute posterior vitreous detachment (PVD) and that is associated with RRD. ${ }^{[2,3]}$ The two patients had these symptoms. The second patient had lattice degeneration which itself is a risk factor for RRD. ${ }^{[4]}$

The mention that RRD was just barraged with laser in the first patient in both eyes also needs explanation. The argument that topiramate causes ciliochoroidal effusion and subsequent angle closure is a known side-effect. ${ }^{[5-8]}$ But RRD occurs due to a different pathomechanism involving PVD, occurrence of a retinal hole and subretinal fluid. ${ }^{[9]}$ Not all patients of RRD need to be having preexisting retinal tears.

We conclude that trying to associate use of topiramate and RRD is far fetched and may unduly influence physicians not to use the drug in myopes.

Sribhargava Natesh

Narayana Nethralaya Superspeciality Eye Hospital, 121/c.Chord Road, Rajajinagar, $1^{\text {st }}$ Block, Bangalore-560 079, India. E-mail: sribhargava_natesh@yahoo.com

DOI: $10.4103 / 0028-3886.51308$

\section{References}

1. Dey KK, Das S, Mishra A, Guha G. Retinal detachment presumably associated with topiramate. Neurol India 2008;56:2:204-5.

2. Novak MA, Welch RB. Complications of acute symptomatic posterior vitreous detachment. Am Ophthalmol 1984;97:308-14.

3. Byer NE. Natural history of posterior vitreous detachment with early management as the premier line of defence against retinal detachment. Ophthalmology 1994;101:1503-13.

4. Green WR, Sebag J. Vitreoretinal interface. In: Ryan SJ, editor. Retina. $4^{\text {th }}$ ed. Mosby; 2006. p. 114:1921.

5. Fraunfelder FW, Fraunfelder FT, Keates EU. Topiramate-associated acute, bilateral, secondary angle-closure glaucoma. Ophthalmology 2004;111:109-11.

6. Rhee DJ, Goldberg MJ, Parrish RK. Bilateral angle-closure glaucoma and ciliary body swelling from topiramate. Arch Ophthalmol 2001;119:1721-3.

7. Desai CM, Ramchandani SJ, Bhopale SG, Ramchandani SS. Acute myopia and angle closure caused by topiramate: A drug used for prophylaxis of migraine. Indian J Ophthalmol 2006;54:195-7.

8. Giuliari GP, Banda RM, Vann VR, Gonzalez VH, McMillin RB. Closed-angle glaucoma after topiramate therapy for migraine in a 


\section{Letters to Editor}

patient with undiagnosed pseudotumor cerebri. Can J Ophthalmol 2008;43:371.

9. Oh KT, Hartnett ME, Landers MB $3^{\text {rd }}$. Pathogenetic mechanisms of retinal detachment. In: Ryan SJ, editor. Retina. $4^{\text {th }}$ ed. Mosby; 2006. p. 116:2013.

Accepted on 06-03-2009 